\title{
Research on Immersive Teaching Innovation of Real Estate Development Based on BIM Simulation

\author{
Jian-Xun DENG ${ }^{1, *}$
}

\author{
1. School of Architecture \& Civil Engineering, Xiamen University Xiamen 361005, Fujian, China \\ ${ }^{*}$ Corresponding author. Jianxun Deng (1974-), male, Assistant Professor and Ph.D. Email: djxun21cn@sina.com
}

\begin{abstract}
In order to strengthen the teaching innovation and reform of real estate development course, aiming at the weak situation of practice teaching of real estate development course for graduate students, this paper proposes to introduce the new BIM modeling technology and adopt the teaching method of "immersive learning" to improve the effect of practice teaching.This innovative teaching mode takes a real project as the prototype, and simulates the whole process of real estate development through BIM virtual simulation. Postgraduates can personally experience each stage of real estate development, as well as the corresponding job responsibilities and tasks in the "immersive learning".In each link of the simulation exercise, role exercise and BIM virtual simulation enhance the practicability and interest of the course, stimulate the subjective initiative of graduate students' independent learning, and cultivate their innovative spirit and innovation ability.
\end{abstract}

Keywords: Real estate development, BIM virtual simulation, Immersion learning, the teaching innovation

\section{BACKGROUND OF REAL ESTATE TEACHING REFORM}

In order to promote and deepen the reform of higher education, promote the innovation and entrepreneurial ability of college students in higher education, and improve the quality of talent cultivation ${ }^{[1]}$, Xiamen University puts forward the education-teaching reform as the core, continuously strengthening the joint efforts of collaborative education of education reform ideas ${ }^{[2]}$, focusing on cultivating students' innovation spirit, entrepreneurial consciousness and innovation and entrepreneurial ability. Under the background of such educational reform, aiming at the weakness of the practical teaching of the civil engineering and engineering management graduate students in Real Estate Development, this paper puts forward the introduction of the new BIM (Building Information Modeling), through the integration of the students to play the role, adopting the teaching method of "immersion learning"[3], combining theory with practice, the whole process of real estate development is simulated based on BIM, and the teaching innovation mode of real estate development simulation drill is carried out.

\section{RESEARCH STATUS OF REAL ESTATE TEACHING REFORM}

At present, some teachers have discussed the teaching reform in the teaching research of undergraduate real estate courses, which has promoted the development of related disciplines. For example, some teachers use physical sand table simulation to realize the simulation of real estate development projects to make up for the shortage of theoretical teaching and achieve certain teaching experimental effects ${ }^{[4][5]}$. Some teachers use the sand table simulation training system developed and operated by real estate enterprises to explore the practical teaching course for undergraduate students ${ }^{[6]}$. Some teachers also propose to use work process-based to design teaching content, highlight the key points and optimize the decomposition of practical training teaching.

There are still some deficiencies in the teaching methods and teaching methods of Real Estate Development, especially in the practical teaching of graduate students. At present, the teachers mainly adopt the teaching method of classroom theoretical lectures for teaching this kind of graduate courses, and students learn passively, which cannot promote active exploration and research for graduate students. The study of concepts and theories related to real estate only 
makes the postgraduates feel that the knowledge they learn is both boring and not conducive to the cultivation of the postgraduate spirit of innovation. In addition, the current sand table simulation teaching research is mainly based on the entity sand table to carry out teaching simulation training ${ }^{[6]}$. Physical sand table model has some limitations, such as long production cycle, inflexible planning and design, inconvenient design model change, single display effect, inconvenient error correction, inconvenient simulation of various development stages, etc. Especially in the COVID-19 prevention and control period, the school implemented online, online and offline hybrid network teaching, if the solid sand table model is adopted, it is not easy to carry out online teaching on line. But the BIM technology can get good effect in online teaching.

Therefore, BIM technology is introduced into the real estate sand table simulation teaching in the course reform. The BIM virtual simulation sand table simulates real estate development exercises aims to integrate students' role-playing, adopt immersion learning method, apply BIM to build virtual sand table model, single building information model, construction site layout model, construction simulation model, and conduct virtual simulation drill for real estate development, so as to achieve the purpose of immersion learning and application of real estate development knowledge.

\section{SPECIFIC CONTENTS OF BIM VIRTUAL SIMULATION SAND TABLE SIMULATION EXERCISE}

(1) Project team formation. According to the group of 5-6 people to form a project team, covering the whole life cycle of real estate major positions, each student corresponds to a different professional position, to carry out cooperative development. Team name design, team logo design, etc.

(2) The virtual sand table construction and environment analysis of development plot. BIM Technology is applied to construct the hypothetical auction plot, including the surrounding environment of the plot. Assuming that a certain plot is about to be auctioned, each group will conduct preliminary feasibility study, including investigation and analysis of macro and micro environment of real estate market, investigation and analysis of competitors and competing products, demand investigation and analysis, etc.

Project profile: a residential real estate development site is located in the international logistics park of a city, adjacent to the east-west navigation road across the city, to the south third ring road of the city.The residential land covers an area of $55.2 \mathrm{mu}$, the plot ratio is 3.0 , the total development building area is 110400 square meters, the building density is $25 \%$, the building height limit is less than 100 meters, and a kindergarten needs to be built for supporting public buildings. Real estate development plot location map (as shown in Figure 1) with the help of Google Earth and other tools, realize the consistency of virtual simulation plot and field plot.

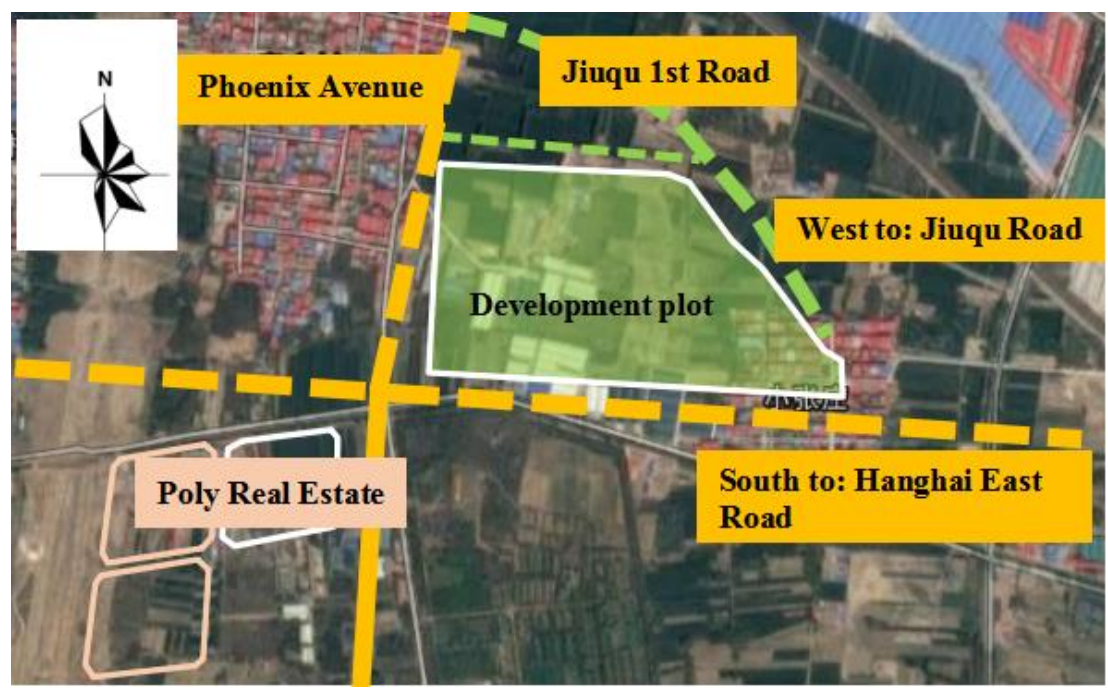

Fig.1 Location of Real Estate Development Plot

(3) Land evaluation and bidding. The main contents include the investigation and analysis of urban land supply and demand, the selection of target land, the calculation of land cost and expenses, the bidding of land, etc.
(4) Project positioning and planning. Including overall development positioning, competitive product research and analysis, target customer group positioning, product positioning and planning, project market positioning, product price positioning, project 
development planning, etc.

(5) Project investment calculation. Feasibility study and investment decision, project investment calculation, project economic benefit evaluation, cost analysis, risk analysis, etc.

(6) Project financing. Financing channels, capital structure, cost and benefit analysis, credit policy analysis, risk analysis, capital balance plan, etc.
(7) BIM virtual simulation sand table model construction and planning and Design: according to the market survey, BIM Technology is used to draw up development and design scheme, build virtual simulation sand table model (as shown in Figure 2), carry out project layout planning and design, architectural appearance design, architectural function layout design, fine decoration design, greening and landscape design, etc.

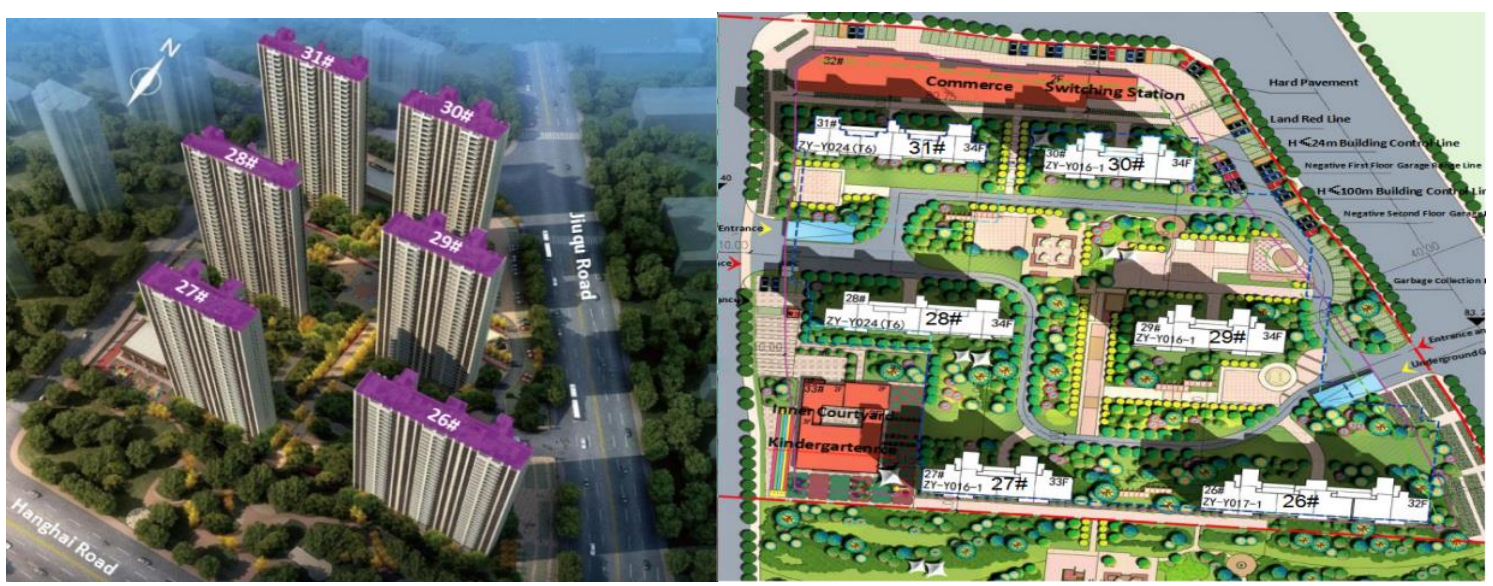

Fig.2 BIM Virtual Sand Table Model Construction of a Real Estate Development Project

(8) Construction bidding and construction management: selection and bidding of construction units, quality and safety management, schedule management, cost management, construction plan guidance, etc. The proposed development project rents 500 meters west of the site as a temporary living area to meet the office and basic living needs of site management staff, and applies BIM technology to the overall layout of the construction office and living area of the real estate development project (as shown in Figure 3).

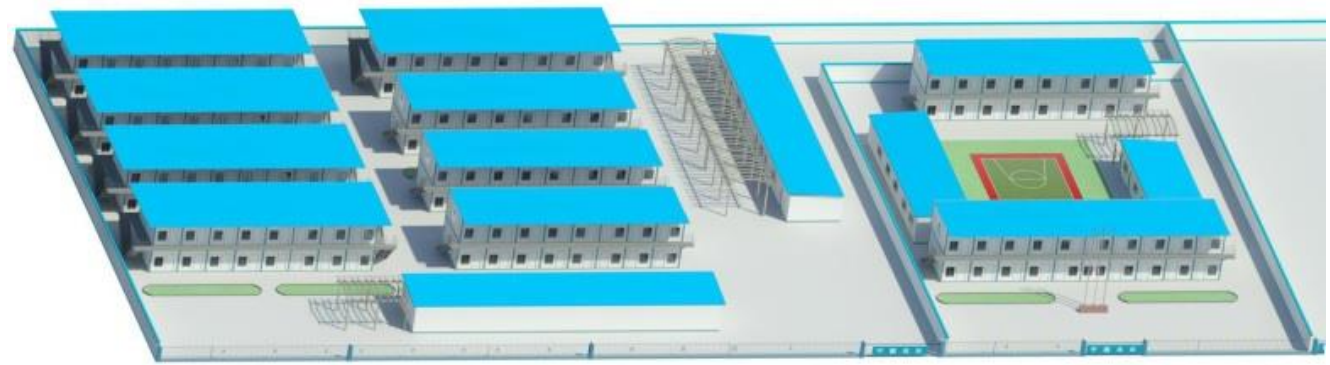

Fig.3 BIM Simulation Effect of Office and Living Area

BIM technology is applied to the general layout of construction site (as shown in Figure 4), foundation

construction planning and virtual simulation of main construction (as shown in Figure 5).
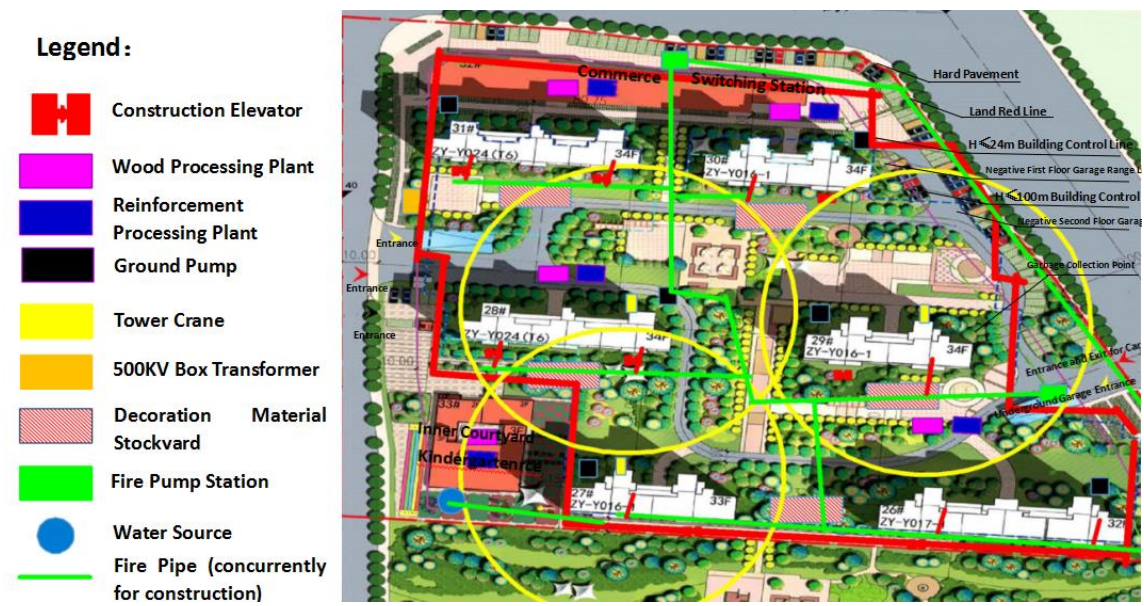

Fig.4 General Layout of BIM Simulation in Construction Site 


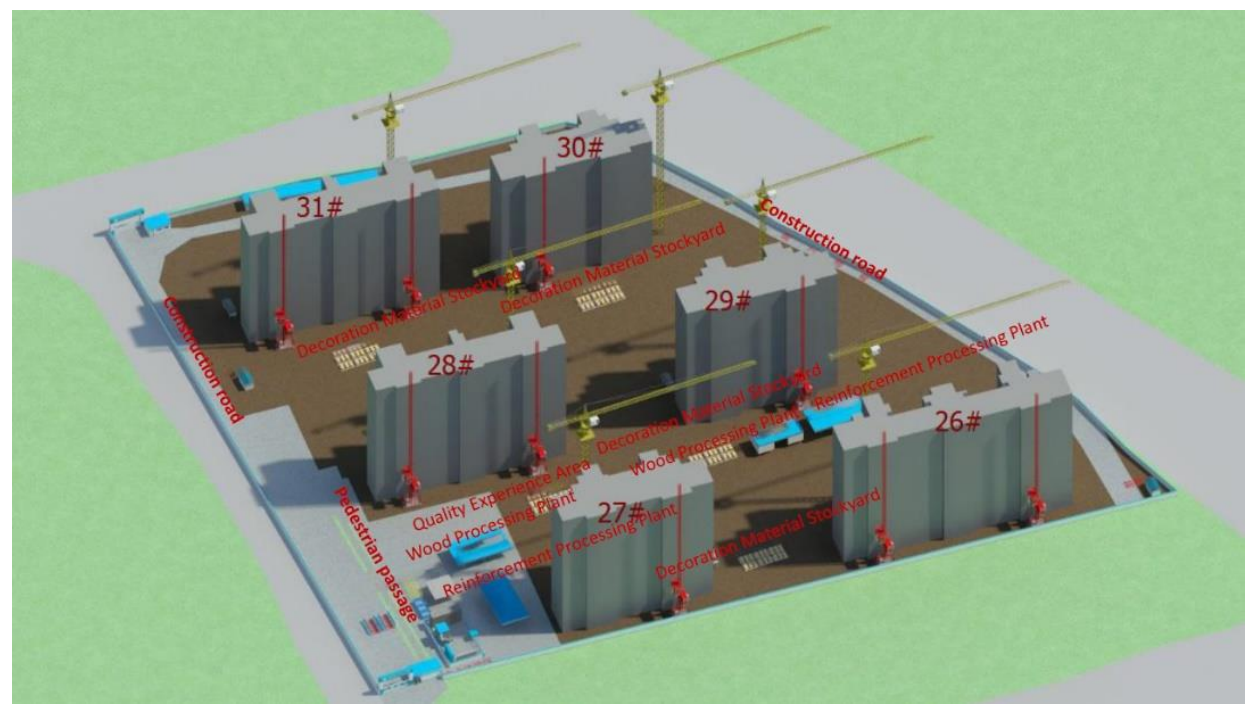

Fig.5 BIM Virtual Simulation Effect of Main Construction

In the construction stage of facade decoration, BIM technology can be applied to virtual simulation of facade decoration construction and dynamic simulation of the whole process of project construction.

(9) Marketing and sales: marketing strategy, case name planning, image and selling point planning, advertising and marketing cost budget, sales agency preference, marketing or investment strategy, etc.

(10) Property operation management: property operation management concept, property operation management scheme, application of BIM simulation for property operation and maintenance management, etc.

\section{CONCLUSION}

Through teaching reform practice, it is shown that the virtual sand table simulation teaching based on BIM provides students with a near real learning environment. Students can fully experience the scenes of different stages of real estate development through model construction, virtual animation roaming and immersion learning. Students play different roles in different positions in the group, which is conducive to students' control of the professional knowledge system, and enhances students' communication ability and team spirit. Through personal practice and role-playing, students will recognize the importance of strengthening communication and cooperation among enterprises, enterprises and project members. Through BIM virtual simulation, the learning tasks in each development stage are completed, which stimulates students' interest in learning, cultivates students' innovative consciousness and spirit, promotes students' understanding of real estate development professional knowledge, and enhances students' ability to comprehensively analyze and solve problems.

\section{ACKNOWLEDGMENT}

This paper is the research achievement of the "2019 Xiamen University Teaching Reform Research Project (Postgraduate) Research on the Teaching Reform of the Real Estate Development Project Management Training Course Based on Sand Table Case Simulation" (2019).

\section{REFERENCES}

[1] State Council General Office on deepening the implementation of innovation and entrepreneurship education reform in institutions of higher learning (No. 36[2015] of the state administration of China), [OL].http://www.gov.cn/zhengce/content/2015-05/ 13/content_9740.htm

[2] Xiamen University deepening the Reform of Innovation and Entrepreneurship Education, [OL].http://www.moe.gov.cn/s78/A08/gjs_left/s385 4/cxcyjy_ssfa/201603/t20160315_233609.html

[3] Immersive Learning, OL].https://baike.baidu.com/item/\%E6\%B2\%89\% E6\%B5\%B8\%E5\%BC\%8F\%E5\%AD\%A6\%E4\% $\mathrm{B} 9 \% \mathrm{~A} 0 / 15656594$ ? $\mathrm{fr}=$ aladdin

[4] Wang Xiaoshu. Application of Enterprise Sand Table Simulation Method in Real Estate Teaching [J]. Journal of Mudanjiang University, 2014,23(04): $165-166$

[5] Xiao Yan. Exploration on Sand Table Experiment Teaching of Real Estate Operation and Management Course [J]. Higher Architectural Education, 2013,22(01): 130-134.

[6] Chen Hongxia. Discussion on the Functions and Existing Problems of Real Estate Sand Table Simulation Course [J]. Curriculum Education Research, 2012(26): 247-248. 